\title{
Risk Stratification of T1 Colorectal Cancer Metastasis to Lymph Nodes: Current Status and Perspective
}

\author{
Katsuro Ichimasa ${ }^{1}$, Shin-ei Kudo ${ }^{1}$, Hideyuki Miyachi' ${ }^{1}$ Yuta Kouyama ${ }^{1}$, Masashi Misawa ${ }^{1}$, and Yuichi Mori ${ }^{1,2}$ \\ ${ }^{1}$ Digestive Disease Center, Showa University Northern Yokohama Hospital, Yokohama, Japan, and ${ }^{2}$ Clinical Effectiveness Research \\ Group, Institute of Health and Society, University of Oslo, Oslo, Norway
}

\author{
Article Info \\ Received July 20, 2020 \\ Revised August 23, 2020 \\ Accepted October 3, 2020
}

Corresponding Author

Katsuro Ichimasa

ORCID https://orcid.org/0000-0001-6675-1219

E-mail ichitommy14@yahoo.co.jp

\begin{abstract}
With the widely spreading population-based screening programs for colorectal cancer and recent improvements in endoscopic diagnosis, the number of endoscopic resections in subjects with T1 colorectal cancer has been increasing. Some reports suggest that endoscopic resection prior to surgical resection of $\mathrm{T} 1$ colorectal cancer has no adverse effect on prognosis and contributes to this tendency. The decision on the need for surgical resection as an additional treatment after endoscopic resection of T1 colorectal cancer should be made according to the metastasis risk to lymph nodes based on histopathological findings. Because lymph node metastasis occurs in approximately $10 \%$ of patients with T1 colorectal cancer according to current international guidelines, the remaining $90 \%$ of patients may be at an increased risk of surgical resection and associated postoperative mortality, with no clinical benefit derived from unnecessary surgical resection. Although a more accurate prediction system for lymph node metastasis is needed to solve this problem, risk stratification for lymph node metastasis remains controversial. In this review, we focus on the current status of risk stratification of T1 colorectal cancer metastasis to lymph nodes and outline future perspectives. (Gut Liver 2021;15:818-826)
\end{abstract}

Key Words: Lymph node metastasis; Treatment strategy; T1 colorectal cancer; Endoscopic resection; Surgical resection

\section{INTRODUCTION}

Colorectal cancer (CRC) is the fourth commonest cancer worldwide with an estimated age-standardized incidence rate of 19.7/100,000 and is the third leading cause of cancer-related death with an estimated age-standardized mortality of $8.9 \%$ in $2018 .{ }^{1}$ With the prevalence of population-based screening programs for CRC and recent rapid progress in endoscopic techniques, the number of endoscopic resections in early CRC has been increasing. ${ }^{2,3}$ Intramucosal cancers are reported to have no potential for lymph node metastasis (LNM), which are an acceptable indication for endoscopic resection. ${ }^{4,5}$ On the other hand, approximately $10 \%$ of patients with submucosal invasion (T1) CRCs have LNM and therefore subsequently require intestinal resection with lymph node dissection after endoscopic resection for cure.

Decisions on surgical resection as an additional treat- ment after endoscopic resection of T1 CRCs are made on the basis of results of pathological findings of the endoscopically resected specimens and usually in accordance with established guidelines, such as those of the National Comprehensive Cancer Network (NCCN)/American Society for Gastrointestinal Endoscopy (ASGE), the European Society for Medical Oncology (ESMO)/European Society of Gastrointestinal Endoscopy (ESGE), the Korean clinical practice guidelines, or the Japanese Society for Cancer of the Colon and Rectum (JSCCR). ${ }^{6-13}$ However, even following these guidelines, LNM occurs in only $6 \%$ to $16 \%$ of such patients. ${ }^{14-23}$ Most patients without LNM are routinely exposed to the risk of surgical resection with an associated postoperative mortality rate of $1.5 \%$ to $2 \%$ and no clinical benefit. ${ }^{24}$ To reduce these unnecessary surgical resections and provide patients with proper treatment without excess or deficiency, development of a more accurate prediction model for LNM is necessary. 
This review focuses on up-to-date information about risk stratification of T1 CRC metastasis to lymph nodes and outlines further perspectives on determining whether patients should undergo additional surgical resection after endoscopic resection of T1 CRC.

\section{CURABILITY IN THE CURRENT GUIDELINES}

The indication criteria for surgical resection as an additional treatment after endoscopic resection of T1 CRC have been defined in the United States, European, Korean, and Japanese guidelines (Table 1). ${ }^{6-13}$ When the vertical margin is positive, surgical resection is recommended. When the vertical margin is negative, if any of the following findings is observed during histopathological examination of the resected specimen, surgical resection with lymph node dissection is recommended: (1) depth of submucosal invasion; (2) lymphovascular invasion; (3) poorly differentiated adenocarcinoma, signet-ring cell carcinoma, or mucinous carcinoma; (4) tumor budding. Table 2 presents risk factors for LNM from multivariate analyses of studies with more than 400 cases of T1 CRC. ${ }^{14,17-21,25-28}$ Studies using the same database in the Surveillance, Epidemiology, and End Results (SEER) included one with a longer study period. ${ }^{19,29}$ As mentioned in each guideline, lymphovascular invasion (odds ratio [OR], 4.4 to 10.199), histological differentiation (OR, 2.09 to 18.444), tumor budding (OR, 1.70 to 2.350 ), and depth of submucosal invasion (OR, 2.14 to 5.404) were reported in many studies to be the main risk factors for LNM in T1 CRCs.

\section{ADDITIONAL RISK FACTORS FOR LNM}

Several studies have referred to predictive factors other than those of the guidelines to stratify more accurately the metastasis risk to lymph nodes in T1 CRC. Risk factors previously reported have included tumor location, patient's sex and age, the status of muscularis mucosae, and the volume of carcinoma, among others.

Table 1. Curability Criteria for Endoscopic Resection of T1 Colorectal Cancer According to Four Guidelines

\begin{tabular}{lcccc}
\hline & $\begin{array}{c}\text { Lymphovascular } \\
\text { invasion }\end{array}$ & $\begin{array}{c}\text { Histological } \\
\text { grade }\end{array}$ & $\begin{array}{c}\text { Depth of } \\
\text { submucosal } \\
\text { invasion }\end{array}$ & $\begin{array}{c}\text { Tumor } \\
\text { budding }\end{array}$ \\
\hline USA $^{8,11,13}$ & 0 & 0 & 0 & 0 \\
Europe $^{7,9,10}$ & 0 & 0 & 0 & \\
Korea $^{12}$ & 0 & 0 & 0 & 0 \\
Japan $^{6}$ & 0 & 0 & 0 & 0 \\
\hline
\end{tabular}

Many studies investigated tumor location, specifically colon and rectum, as a predictive factor for LNM in T1 CRC. Some authors reported that $\mathrm{T} 1$ rectal cancer showed a higher rate of LNM than T1 colon cancer. ${ }^{17,25,30-32}$ By contrast, others reported that there was no significant difference in LNM between rectum and colon. ${ }^{18,33-37}$ Bosch et al. ${ }^{16}$ conducted a systematic review of 10 studies including a total of 2,722 T1 CRC patients. They concluded that rectum was a risk factor for LNM (rectum $13.8 \%$ vs colon 9.9\%: relative risk, $1.4 ; 95 \%$ confidence interval [CI], 1.1 to 1.7; $\mathrm{p}<0.001)$. Several studies have divided tumor location into left- and right-sided CRCs, ${ }^{19,38-40}$ all of which concluded that left-sided T1 CRCs (10.8\% to $12.0 \%)$ showed a significantly higher rate of LNM than right-sided tumors (4.8\% to $5.4 \%)$. Genetic or anatomical features may affect these differences. Taken together, the results show that tumor location could be an effective predictor for LNM in T1 CRC.

Recently, patients' sex was reported to be a predictive factor for LNM in T1 CRC. Miyachi's group firstly referred to female sex as a predictor (OR, 2.22; 95\% CI, 1.26 to 3.91) and thereafter conducted a systematic review and metaanalysis to assess whether patients' sex was predictive of LNM. ${ }^{14,41}$ This meta-analysis analyzing four studies from Japan showed an association between female sex and the risk of LNM (OR, 2.45; 95\% CI, 1.03 to 3.88). In reports from Korea and China (data from SEER), female sex was also a significant independent risk factor for LNM. ${ }^{19,42} \mathrm{Al}-$ though the mechanism underlying the higher rate of LNM in female patients has remained unclear, epidemiological studies have reported a potential association between sex hormones and CRC. ${ }^{43,44}$ The advantage of tumor location and patients' sex lies in the fact that these are objective indicators, unlike other pathological risk factors.

The muscularis mucosae is a thin, smooth muscle layer that can be observed in the main parts of the alimentary canal. Risk of metastasis is negligible in CRCs when the tumors have not extended beyond the muscular mucosae. The status of muscularis can be classified into two or three categories. In the two-category designation, the status of muscularis mucosae is classified as maintenance or disappearance. Few patients with maintenance muscularis mucosae had LNM ( $0 \%$ to $2 \%$ ), whereas $10 \%$ to $16 \%$ of patients with disappearance muscularis mucosae presented with LNM ( $\mathrm{p}=0.026$ and $\mathrm{p}=0.02$ ) followed by good reproducibility, with a kappa value of 0.67 between two pathologists. ${ }^{14,45}$ In the three-category designation, the status of muscularis mucosae was classified as possible to identify (type A), incomplete disruption (type B), or complete disappearance (type C). No patients with type A had LNM $(0 \%, 0 / 46)$, and the type $C$ group $(17.3 \%, 31 / 210)$ was 
Table 2. Risk Factors for LNM on Multivariate Analysis of Patients with T1 Colorectal Cancers ( $>400$ Cases)

\begin{tabular}{|c|c|c|c|c|c|}
\hline Author (year) & Country & No. of patients & LNM rate, \% & Risk factors & OR $(95 \% \mathrm{Cl})$ \\
\hline Rönnow et al. $(2020)^{18}$ & Sweden & 1,439 & 10 & $\begin{array}{l}\text { Lymphovascular invasion } \\
\text { Differentiation } \\
\text { Perineural invasion } \\
\text { Age (younger) }\end{array}$ & $\begin{array}{l}7.311(4.582-11.665) \\
2.451(1.302-4.613) \\
9.717(2.856-33.064) \\
2.654(1.670-3.935)\end{array}$ \\
\hline Guo et al. $(2020)^{19}$ & $\begin{array}{l}\text { China } \\
\text { (data from SEER) }\end{array}$ & 17,309 & 13.24 & $\begin{array}{l}\text { Differentiation (ref; well) } \\
\text { Moderately } \\
\text { Poorly } \\
\text { Undifferentiated } \\
\text { Histology (mucinous) } \\
\text { Tumor location (left-sided) } \\
\text { Tumor size (ref; 1-9 mm) } \\
10-19 \mathrm{~mm} \\
30 \mathrm{~mm}- \\
\text { Age (ref; } 18-49 \text { yr) } \\
50-64 \text { yr } \\
65-79 \text { yr } \\
\geq 80 \text { yr } \\
\text { Sex (male) } \\
\text { Race (Asian, Pacific Islander) } \\
\text { CEA } \\
\text { Years of diagnosis (ref; 2004-2007) } \\
2012-2016 \\
\text { Marital status (unmarried) }\end{array}$ & $\begin{array}{l}1.76(1.53-2.04) \\
3.99(3.31-4.81) \\
2.33(1.50-3.53) \\
2.19(1.70-2.80) \\
1.59(1.43-1.76) \\
\\
1.24(1.07-1.44) \\
1.56(1.34-1.81) \\
0.86(0.75-0.99) \\
0.61(0.53-0.71) \\
0.46(0.37-0.57) \\
0.81(0.74-0.89) \\
1.19(1.02-1.39) \\
0.83(0.70-0.99)\end{array}$ \\
\hline Yasue et al. $(2019)^{17}$ & Japan & 846 & 8.7 & $\begin{array}{l}\text { Lymphovascular invasion } \\
\text { Differentiation } \\
\text { Tumor budding }\end{array}$ & $\begin{array}{l}8.09(3.84-17.1) \\
2.09(1.12-3.89) \\
1.89(1.09-3.29)\end{array}$ \\
\hline Oh et al. $(2019)^{20}$ & Korea & 833 & 11.6 & $\begin{array}{l}\text { Vascular invasion } \\
\text { Differentiation } \\
\text { Depth of SM invasion } \\
\text { Tumor budding } \\
\text { Background adenoma }\end{array}$ & $\begin{array}{l}8.45(4.56-15.66) \\
7.89(2.89-21.52) \\
2.14(1.19-3.86) \\
1.70(1.03-2.80) \\
0.58(0.36-0.92)\end{array}$ \\
\hline Belderbos et al. (2017) & Netherlands & 796 & 10.3 & $\begin{array}{l}\text { High-risk histology* } \\
\text { Tumor location (ref; proximal colon) } \\
\text { Distal colon } \\
\text { Rectum } \\
\text { Lymph nodes evaluated (ref; } n=1-3 \text { ) } \\
\quad n=4-7 \\
n=8-11\end{array}$ & $\begin{array}{l}2.299(1.025-5.160) \\
2.442(1.148-5.192) \\
2.496(1.175-5.304) \\
2.640(1.171-5.951)\end{array}$ \\
\hline Ha et al. $(2017)^{28}$ & Korea & 745 & 12.2 & $\begin{array}{l}\text { Vascular invasion } \\
\text { Differentiation } \\
\text { Tumor budding } \\
\text { Depth of SM invasion }\end{array}$ & $\begin{array}{l}6.631(3.671-11.979) \\
7.340(2.623-20.535) \\
1.757(1.044-2.955) \\
2.193(1.207-3.984)\end{array}$ \\
\hline Miyachi et al. $(2016)^{1 / 4}$ & Japan & 653 & 9.2 & $\begin{array}{l}\text { Lymphovascular invasion } \\
\text { Differentiation } \\
\text { Tumor budding } \\
\text { Sex (female) }\end{array}$ & $\begin{array}{l}9.84(3.42-28.3) \\
2.31(1.25-4.27) \\
1.80(1.01-3.21) \\
2.22(1.26-3.91)\end{array}$ \\
\hline Suh et al. $(2012)^{27}$ & Korea & 435 & 13.0 & $\begin{array}{l}\text { Lymphovascular invasion } \\
\text { Differentiation } \\
\text { Tumor budding } \\
\text { Absence of BGA }\end{array}$ & $\begin{array}{c}10.199(3.710-28.041) \\
18.444(3.767-90.296) \\
2.350(1.054-5.239) \\
2.612(1.226-5.568)\end{array}$ \\
\hline Okabe et al. $(2004)^{25}$ & USA, Japan & 428 & 10 & $\begin{array}{l}\text { Lymphovascular invasion } \\
\text { Depth of SM invasion }\end{array}$ & $\begin{array}{l}4.4(1.7-11) \\
2.7(1-7.5)\end{array}$ \\
\hline Kitajima et al. $(2004)^{26}$ & Japan & 865 & 10.1 & $\begin{array}{l}\text { Lymphatic invasion } \\
\text { Depth of SM invasion } \\
\text { Sprouting }\end{array}$ & $\begin{array}{l}4.691(2.768-7.950) \\
5.404(1.623-17.933) \\
2.276(1.350-3.835)\end{array}$ \\
\hline
\end{tabular}

LNM, lymph node metastasis; OR, odds ratio; Cl, confidence interval; SEER, Surveillance, Epidemiology, and End Results; CEA, carcinoembryonic antigen; SM, submucosal; BGA, background adenoma.

*High-risk histology includes poor/no differentiation, deep SM invasion (sm2/sm3), and/or lymphovascular invasion. 
significantly correlated with LNM in multivariate analysis $(\mathrm{p}=0.012, \mathrm{OR}=3.38) .{ }^{46}$ In addition, the area of submucosal invasion was reported to be a potential predictor of LNM. Toh et al. ${ }^{47}$ investigated the correlation between the total areas of carcinoma in submucosal layer and the presence of LNM, and reported the significant correlation $(\mathrm{p}<0.001)$. In this study, the cutoff value was $35 \mathrm{~mm}^{2}$ for area of submucosal invasion. Comprehensively considering the above findings, the status of muscularis mucosae was considered to be associated with the horizontal extent or the total area of carcinoma invasion, and thus these indicators (rather than the vertical depth of invasion) could precisely reflect the risk of LNM.

Concerning other factors, younger age, race, tumor size, carcinoembryonic antigen, and absence of background adenoma were also reported to be associated with LNM. ${ }^{18-20,27,29}$ At least now, however, it is difficult to apply these as significant LNM risk factors to actually perform additional surgical resection, and further studies will be needed in the future.

\section{PROBLEMS OF PATHOLOGICAL DIAGNOSIS}

Lymphovascular invasion was found to be the most powerful predictor of LNM in many studies. Lymphatic or vascular invasion was defined as invasion of tumor cells into lymphatic vessels or blood vessels. ${ }^{48-51}$ Although lymphovascular invasion can be diagnosed by hematoxylin and eosin (H\&E) staining, additional staining techniques such as immunohistochemical stains (e.g., D2-40) or Victoria blue and Elastica van Gieson (EVG) have been used by some pathologists. ${ }^{52,53}$ Despite its high importance as a risk factor, observation of lymphovascular invasion is hampered by its weakness of high interobserver variability between pathologists. Some articles report poor interobserver concordance of lymphovascular invasion assessment. Kojima et al. $^{49}$ reported that agreement regarding lymphatic and vascular invasion in Japan produced kappa values of 0.216 (95\% CI, 0.133 to 0.299 ) and 0.524 (95\% CI, 0.441 to 0.606), respectively. Among United States and European pathologists, agreements were 0.518 ( 0.379 to 0.657$)$ and 0.543 (0.405 to 0.682$)$, respectively, for lymphatic invasion and 0.545 (0.407 to 0.684$)$ and 0.560 (0.422 to 0.699$)$ for vascular invasion. ${ }^{54}$ Additional staining techniques increased interobserver agreement in lymphatic invasion from kappa value of 0.30 for $\mathrm{H} \& \mathrm{E}$ staining to 0.56 for D240 staining, and in vascular invasion from kappa 0.10 for $\mathrm{H} \& \mathrm{E}$ staining to 0.48 for EVG staining. ${ }^{55}$ In addition, lymphatic invasion diagnosed with D2-40 was reported to be a better indicator of LNM than H\&E staining (OR 2.664 with HE vs 6.048 with D2-40). ${ }^{56}$ Although the concordance in lymphovascular invasion was not good, additional staining was found to improve the interobserver agreement among pathologists. ${ }^{57}$ In the near future, standardization of staining methods and diagnostic criteria should become a global requirement while also bearing in mind costeffectiveness.

Histological grade is also stated as a risk factor in all guidelines. According to World Health Organization Classification of Tumours, grading is based on the least differentiated component. ${ }^{58}$ On the other hand, as there is no definition on whether to assess histological grade using the most dominant or poorest components in some guidelines, standardization is required. Depth of submucosal invasion as a risk factor was evaluated according to Kudo classification (sm1, sm2, or sm3) or the depth of submucosal invasion (in micrometers). ${ }^{48,59}$ In both cohorts, invasion depth was associated with the presence of LNM (OR, 2.14 to 5.404). However, some research groups have reported that depth of submucosal invasion was not a predictive factor for LNM. ${ }^{18,60}$ Japanese guidelines describe that the incidence of LNM is extremely low, $1.3 \%$ (95\% CI, $0 \%$ to $2.4 \%$ ), in cases with an invasion depth of $1,000 \mu \mathrm{m}$ or more without risk factors for LNM (other than the invasion depth). ${ }^{6}$ In addition, in assessing the invasion depth, the problem is that the interobserver agreement among pathologists is low and tumor morphology is not taken into consideration. ${ }^{60}$

\section{ENDOSCOPIC RESECTION AS A FIRST-LINE TREATMENT}

By virtue of recent progress in colonoscopy and diagnostic approaches, many T1 CRCs that were previously treated by radical surgical resections can now be resected endoscopically. ${ }^{61}$ Endoscopic submucosal dissection (ESD) is effective for en bloc resection of superficial colorectal lesions regardless of tumor size or location and enables accurate histopathological assessment. ${ }^{62,63}$ Endoscopic resection prior to surgical resection has potential adverse effects because endoscopic maneuvers can violate the concept of a "no-touch isolation technique," and induce the risk of metastasis. However, several studies have reported that endoscopic resection of $\mathrm{T} 1 \mathrm{CRC}$ before surgical resection does not affect adverse events and recurrence. ${ }^{64-69}$ Overwater et al. ${ }^{64}$ described that no significant differences were observed between primary and secondary surgical resection for the presence of LNM (OR, 0.97; 95\% CI, 0.49 to 1.93 ; $\mathrm{p}=0.940$ ) and recurrence (hazard ratio, 0.97 ; $95 \% \mathrm{CI}, 0.41$ to 2.34 ; $\mathrm{p}=0.954)$. Moreover, Yamashita et al. ${ }^{65}$ and Yamaoka et al. ${ }^{66}$ reported that there were no significant differences 
between primary and secondary surgery groups regarding recurrence after propensity-score matching ( $1.9 \%$ vs $3.1 \%$, $\mathrm{p}=0.4740$ and $1.3 \%$ vs $1.3 \%, \mathrm{p}=1.00$, respectively). In addition, unfavorable histological features of T1 CRCs apart from depth of invasion, such as lymphovascular invasion, poor differentiation, or tumor budding, cannot be diagnosed with endoscopic findings before resection. Therefore, the "resect and examine" strategy of primary endoscopic resection and histopathological assessment, that is, an attempted en bloc resection of a possible T1 CRC as total excisional biopsy, may be acceptable. Some recent studies reported the effectiveness and safety of endoscopic full-thickness resection for T1 CRC which were difficult to be resected in conventional endoscopic mucosal resection or ESD. Hence, objective histopathological evaluation and an accurate LNM-predicting system are more essential for the "resect and examine" strategy. ${ }^{70-72}$

Although surgical resection with lymph node dissection is a more curative option for T1 CRC than endoscopic resection alone, assessment of whether the oncological benefits of resection of potential positive lymph nodes and possible residual cancer tissue outweigh the risks of secondary surgical resection is challenging. A national cohort study from the Netherlands reported $1.7 \%(87 / 5,170)$ postoperative mortality in T1 CRC, which did not significantly differ from 2.5\% T2-T3 CRC (880/34,643, p=0.604). ${ }^{24}$ Risk of metastasis, operative risk, quality of life, and cost-effectiveness should be taken into consideration when making a decision concerning additional treatment. ${ }^{73}$

\section{RISK-SCORING SYSTEM}

Some studies have developed scoring systems to stratify the risk of LNM in T1 CRC..$^{14,15,19,20,74}$ Backes et al. ${ }^{15}$ reported a prediction model that analyzed five histological factors among 708 T1 CRCs from 13 hospitals: lymphovascular invasion, Haggitt level 4 invasion, muscularis mucosae, poorly differentiated clusters, and tumor budding. Discriminating power of their model outperformed the current guidelines (their model, area under the curve $[\mathrm{AUC}]=0.83$; ASGE/ESGE, AUC=0.67; JSCCR, AUC=0.64). Miyachi et al. ${ }^{14}$ used a decision tree combining five clinicopathological factors: status of muscularis mucosae, lymphovascular invasion, tumor budding, histological grade, and patient's sex. They divided the risk of LNM into four classes and in theory could reduce unnecessary surgical resections by $30 \%$ compared with the current Japanese guidelines. A nomogram using clinicopathological factors obtained from multivariate logistic regression was also reported to be effective in prediction of LNM in some studies. ${ }^{19,20}$ Although
OR tables are the most common way to present predictive models in several disciplines, they do not allow the direct calculation of output probabilities. By contrast, nomograms provide excellent graphical depictions of all variables in the model and provide a quick view of the weight of each variable. Both models showed good discriminatory power, although this was limited by retrospective studies or by conducting internal validations of their models.

\section{PERSPECTIVE: NEW CHALLENGES OF RISK-SCORING SYSTEMS}

\section{Artificial intelligence system}

Several studies have devised novel methods to predict the presence of LNM. A first report using artificial intelligence (AI) as a predicting tool was published in 2018 . $^{75}$ This AI model using support vector machine provides supervised machine-learning analysis of patients' 45 clinicopathological factors such as patient's age and sex, tumor location and size, and lymphovascular invasion obtained before surgical resection, whereby the positivity or negativity for LNM is determined. The diagnostic ability of the AI model was compared with American, European, and Japanese guidelines. Although the sensitivity was $100 \%$ (95\% CI, $72 \%$ to $100 \%$ ) in the AI model and the guidelines, specificity of the AI model and the American, European, and Japanese guidelines was 66\% (95\% CI, 56\% to $76 \%$ ), $44 \%$ ( $95 \%$ CI, $34 \%$ to $55 \%$ ), $0 \%$ ( $95 \%$ CI, $0 \%$ to $3 \%$ ), and $0 \%$ (95\% CI, $0 \%$ to $3 \%)$, respectively, while accuracy was $69 \%$ ( $95 \%$ CI, $59 \%$ to $78 \%$ ), $49 \%$ (95\% CI, 39\% to $59 \%$ ), $9 \%$ ( $95 \%$ CI, $4 \%$ to $16 \%$ ), and $9 \%$ ( $95 \%$ CI, $4 \%$ to $16 \%)$, respectively. Although the AI model showed higher discriminating power than the current guidelines, there were two major limitations. First, it did not include the cases undergoing endoscopic resection alone (which form part of the actual prediction targets), evaluating only the surgical resection cases with lymph node dissection. Second, as it used only internal validation, data for machine learning and validation came from the same institution, which might overestimate the performance of AI because clinicopathological characteristics in the training and testing datasets were similar. To overcome these limitations, the research group is now conducting a multicenter trial including more than 4,000 patients with T1 CRCs from seven hospitals. ${ }^{76}$

\section{Whole-slide image-based prediction}

AI-aided histological evaluation of the colorectal lesion is rapidly emerging. ${ }^{77}$ A random forest algorithm that analyzed whole-slide images of cytokeratin immunohisto- 
chemistry was reported in $2019 .^{78}$ The algorithm analyzed 16 morphological parameters, such as total cancerous area $\left(\mathrm{mm}^{2}\right)$, on a whole-slide digital image. The random forest algorithm showed better LNM predictive ability than the conventional model using pathological risk factors obtained by multivariate analysis ( $\mathrm{AUC}=0.94$ vs $\mathrm{AUC}=0.83$ ). The biggest strength of this model was that the predicted result did not depend on the pathologists. Conventional prediction models using pathological findings diagnosed by pathologists encounter the major problem of interobserver disagreement among the pathologists. Further development of machine learning with larger samples and external validation will be needed to confirm the potential success of this method.

\section{Biomarkers}

A risk-prediction model using a genome-wide small RNA-sequencing approach was reported by a research group in the United States. ${ }^{79,80}$ These investigators identified five microRNAs (MIR32, MIR181B, MIR193B, MIR195, and MIR411) associated with LNM. These microRNAs identified a high-risk group for LNM with an AUC value of 0.82 in the training cohort and 0.74 in the testing cohort. Also, an mRNA classifier composed of eight mRNA genes (AMT, MMP9, FOXA1, LYZ, MMP1, C2CD4A, PIGR, and RCC1) outperformed the current clinical risk-factor assessment in discriminating the presence of LNM (AUC $=0.88$ vs AUC $=0.59$ ). The strengths of their research included the use of a systematic and comprehensive biomarker discovery approach based on highthroughput microRNA-sequencing data analysis and the use of colonoscopy-derived biopsy samples before endoscopic resection despite the limitation of sampling bias because of heterogeneity in the lesion. In addition, evaluation of adenine-thymine-rich interactive domain 1A (ARID1A) protein expression using immunohistochemical staining was reported to be effective in predicting the presence of LNM. $^{81}$

\section{SUMMARY AND CONCLUSIONS}

As the number of endoscopic resections of T1 CRCs increases in the future, more accurate prediction models of LNM will be needed. Standardization of pathological diagnosis criteria is also required to make the risk-stratifying systems more objective. Appropriate treatment strategies are required to prevent unnecessary surgery or recurrence as far as is possible. Given that previous studies included mainly retrospective analyses, verification through prospective studies in real time will also be required.

\section{CONFLICTS OF INTEREST}

No potential conflict of interest relevant to this article was reported.

\section{ORCID}

Katsuro Ichimasa https://orcid.org/0000-0001-6675-1219 Shin-ei Kudo https://orcid.org/0000-0002-4268-1217 Hideyuki Miyachi https://orcid.org/0000-0002-8404-0899 Yuta Kouyama https://orcid.org/0000-0002-9663-247X Masashi Misawa https://orcid.org/0000-0002-8520-2036 Yuichi Mori https://orcid.org/0000-0003-2262-0334

\section{REFERENCES}

1. International Agency for Research on Cancer (IARC). Cancer today [Internet]. Lyon: IARC; c2020 [cited 2020 Dec 9]. Available from: https://gco.iarc.fr/today/home.

2. Bretthauer M, Kaminski MF, Løberg M, et al. Populationbased colonoscopy screening for colorectal cancer: a randomized clinical trial. JAMA Intern Med 2016;176:894-902.

3. Amri R, Bordeianou LG, Sylla P, Berger DL. Impact of screening colonoscopy on outcomes in colon cancer surgery. JAMA Surg 2013;148:747-754.

4. Yoshida N, Naito Y, Inada Y, et al. Cross-national analysis about the difference of histopathological management in Tis and $\mathrm{T} 1$ colorectal cancer between Japan and Korea. J Anus Rectum Colon 2019;3:18-26.

5. Haggitt RC, Glotzbach RE, Soffer EE, Wruble LD. Prognostic factors in colorectal carcinomas arising in adenomas: implications for lesions removed by endoscopic polypectomy. Gastroenterology 1985;89:328-336.

6. Hashiguchi Y, Muro K, Saito Y, et al. Japanese Society for Cancer of the Colon and Rectum (JSCCR) guidelines 2019 for the treatment of colorectal cancer. Int J Clin Oncol 2020;25:1-42.

7. Glynne-Jones R, Wyrwicz L, Tiret E, et al. Rectal cancer: ESMO Clinical Practice Guidelines for diagnosis, treatment and follow-up. Ann Oncol 2018;29:iv263.

8. Benson AB, Venook AP, Al-Hawary MM, et al. Rectal Cancer, Version 2.2018, NCCN Clinical Practice Guidelines in Oncology. J Natl Compr Canc Netw 2018;16:874-901.

9. Pimentel-Nunes P, Dinis-Ribeiro M, Ponchon T, et al. Endoscopic submucosal dissection: European Society of Gastrointestinal Endoscopy (ESGE) Guideline. Endoscopy 2015;47:829-854.

10. Labianca R, Nordlinger B, Beretta GD, et al. Early colon cancer: ESMO Clinical Practice Guidelines for diagnosis, treat- 
ment and follow-up. Ann Oncol 2013;24 Suppl 6:vi64-vi72.

11. Benson AB 3rd, Venook AP, Cederquist L, et al. Colon Cancer, Version 1.2017, NCCN Clinical Practice Guidelines in Oncology. J Natl Compr Canc Netw 2017;15:370-398.

12. Park CH, Yang DH, Kim JW, et al. Clinical practice guideline for endoscopic resection of early gastrointestinal cancer. Clin Endosc 2020;53:142-166.

13. Kaltenbach T, Anderson JC, Burke CA, et al. Endoscopic removal of colorectal lesions-recommendations by the US Multi-Society Task Force on Colorectal Cancer. Gastroenterology 2020;158:1095-1129.

14. Miyachi H, Kudo SE, Ichimasa K, et al. Management of T1 colorectal cancers after endoscopic treatment based on the risk stratification of lymph node metastasis. J Gastroenterol Hepatol 2016;31:1126-1132.

15. Backes Y, Elias SG, Groen JN, et al. Histologic factors associated with need for surgery in patients with pedunculated T1 colorectal carcinomas. Gastroenterology 2018;154:16471659.

16. Bosch SL, Teerenstra S, de Wilt JH, Cunningham C, Nagtegaal ID. Predicting lymph node metastasis in pT1 colorectal cancer: a systematic review of risk factors providing rationale for therapy decisions. Endoscopy 2013;45:827-834.

17. Yasue C, Chino A, Takamatsu M, et al. Pathological risk factors and predictive endoscopic factors for lymph node metastasis of T1 colorectal cancer: a single-center study of 846 lesions. J Gastroenterol 2019;54:708-717.

18. Rönnow CF, Arthursson V, Toth E, Krarup PM, Syk I, Thorlacius H. Lymphovascular infiltration, not depth of invasion, is the critical risk factor of metastases in early colorectal cancer: retrospective population-based cohort study on prospectively collected data, including validation. Ann Surg. Epub 2020 Mar 13. https://doi.org/10.1097/ SLA.0000000000003854.

19. Guo K, Feng Y, Yuan L, et al. Risk factors and predictors of lymph nodes metastasis and distant metastasis in newly diagnosed T1 colorectal cancer. Cancer Med 2020;9:50955113 .

20. Oh JR, Park B, Lee S, et al. Nomogram development and external validation for predicting the risk of lymph node metastasis in T1 colorectal cancer. Cancer Res Treat 2019;51:1275-1284

21. Belderbos TD, van Erning FN, de Hingh IH, van Oijen MG, Lemmens VE, Siersema PD. Long-term recurrence-free survival after standard endoscopic resection versus surgical resection of submucosal invasive colorectal cancer: a population-based study. Clin Gastroenterol Hepatol 2017;15:403411.

22. Kim B, Kim EH, Park SJ, et al. The risk of lymph node metastasis makes it unsafe to expand the conventional indications for endoscopic treatment of T1 colorectal cancer: a retrospective study of 428 patients. Medicine (Baltimore) 2016;95:e4373.

23. Mou S, Soetikno R, Shimoda T, Rouse R, Kaltenbach T. Pathologic predictive factors for lymph node metastasis in submucosal invasive (T1) colorectal cancer: a systematic review and meta-analysis. Surg Endosc 2013;27:2692-2703.

24. Vermeer NCA, Backes Y, Snijders HS, et al. National cohort study on postoperative risks after surgery for submucosal invasive colorectal cancer. BJS Open 2018;3:210-217.

25. Okabe S, Shia J, Nash G, et al. Lymph node metastasis in $\mathrm{T} 1$ adenocarcinoma of the colon and rectum. J Gastrointest Surg 2004;8:1032-1039.

26. Kitajima K, Fujimori T, Fujii S, et al. Correlations between lymph node metastasis and depth of submucosal invasion in submucosal invasive colorectal carcinoma: a Japanese collaborative study. J Gastroenterol 2004;39:534-543.

27. Suh JH, Han KS, Kim BC, et al. Predictors for lymph node metastasis in T1 colorectal cancer. Endoscopy 2012;44:590595.

28. Ha RK, Han KS, Sohn DK, et al. Histopathologic risk factors for lymph node metastasis in patients with T1 colorectal cancer. Ann Surg Treat Res 2017;93:266-271.

29. Xu X, Zhang C, Ni X, et al. Population-based analysis on predictors for lymph node metastasis in $\mathrm{T} 1$ colon cancer. Surg Endosc 2020;34:4030-4040.

30. Wang H, Wei XZ, Fu CG, Zhao RH, Cao FA. Patterns of lymph node metastasis are different in colon and rectal carcinomas. World J Gastroenterol 2010;16:5375-5379.

31. Okuyama T, Oya M, Ishikawa H. Budding as a risk factor for lymph node metastasis in pT1 or pT2 well-differentiated colorectal adenocarcinoma. Dis Colon Rectum 2002;45:628634.

32. Kikuchi R, Takano M, Takagi K, et al. Management of early invasive colorectal cancer: risk of recurrence and clinical guidelines. Dis Colon Rectum 1995;38:1286-1295.

33. Ikematsu H, Yoda Y, Matsuda T, et al. Long-term outcomes after resection for submucosal invasive colorectal cancers. Gastroenterology 2013;144:551-559.

34. Ichimasa K, Kudo SE, Miyachi H, et al. Comparative clinicopathological characteristics of colon and rectal T1 carcinoma. Oncol Lett 2017;13:805-810.

35. Sakuragi M, Togashi K, Konishi F, et al. Predictive factors for lymph node metastasis in T1 stage colorectal carcinomas. Dis Colon Rectum 2003;46:1626-1632.

36. Nascimbeni R, Burgart LJ, Nivatvongs S, Larson DR. Risk of lymph node metastasis in T1 carcinoma of the colon and rectum. Dis Colon Rectum 2002;45:200-206.

37. Oh-e H, Tanaka S, Kitadai Y, Shimamoto F, Yoshihara M, Haruma K. Angiogenesis at the site of deepest penetration predicts lymph node metastasis of submucosal colorectal cancer. Dis Colon Rectum 2001;44:1129-1136. 
38. Ouchi A, Toriyama K, Kinoshita T, et al. Variations in clinical features and oncologic behaviors of $\mathrm{T} 1$ colorectal cancer according to tumor location. Int J Clin Oncol 2020;25:11301136.

39. Mochizuki K, Kudo SE, Ichimasa K, et al. Left-sided location is a risk factor for lymph node metastasis of $\mathrm{T} 1$ colorectal cancer: a single-center retrospective study. Int J Colorectal Dis 2020;35:1911-1919.

40. Son HJ, Song SY, Lee WY, et al. Characteristics of early colorectal carcinoma with lymph node metastatic disease. Hepatogastroenterology 2008;55:1293-1297.

41. Ichimasa K, Kudo SE, Miyachi H, et al. Patient gender as a factor associated with lymph node metastasis in T1 colorectal cancer: a systematic review and meta-analysis. Mol Clin Oncol 2017;6:517-524.

42. Lee YJ, Huh JW, Shin JK, et al. Risk factors for lymph node metastasis in early colon cancer. Int J Colorectal Dis 2020;35:1607-1613.

43. Fernandez E, La Vecchia C, Balducci A, Chatenoud L, Franceschi S, Negri E. Oral contraceptives and colorectal cancer risk: a meta-analysis. Br J Cancer 2001;84:722-727.

44. Grodstein F, Newcomb PA, Stampfer MJ. Postmenopausal hormone therapy and the risk of colorectal cancer: a review and meta-analysis. Am J Med 1999;106:574-582.

45. Tateishi Y, Nakanishi Y, Taniguchi H, Shimoda T, Umemura S. Pathological prognostic factors predicting lymph node metastasis in submucosal invasive (T1) colorectal carcinoma. Mod Pathol 2010;23:1068-1072.

46. Nakadoi K, Oka S, Tanaka S, et al. Condition of muscularis mucosae is a risk factor for lymph node metastasis in T1 colorectal carcinoma. Surg Endosc 2014;28:1269-1276.

47. Toh EW, Brown P, Morris E, Botterill I, Quirke P. Area of submucosal invasion and width of invasion predicts lymph node metastasis in pT1 colorectal cancers. Dis Colon Rectum 2015;58:393-400.

48. Japanese Society for Cancer of the Colon and Rectum. Japanese classification of colorectal, appendiceal, and anal carcinoma: the 3d English Edition [Secondary Publication]. J Anus Rectum Colon 2019;3:175-195.

49. Kojima M, Shimazaki H, Iwaya K, et al. Pathological diagnostic criterion of blood and lymphatic vessel invasion in colorectal cancer: a framework for developing an objective pathological diagnostic system using the Delphi method, from the Pathology Working Group of the Japanese Society for Cancer of the Colon and Rectum. J Clin Pathol 2013;66:551-558.

50. Wang HS, Liang WY, Lin TC, et al. Curative resection of T1 colorectal carcinoma: risk of lymph node metastasis and long-term prognosis. Dis Colon Rectum 2005;48:1182-1192.

51. Tsuruta O, Tsuji Y, Kawano H, et al. Indication for endoscopic resection of submucosal colorectal carcinoma: special reference to lymph node metastasis. Diagn Ther Endosc 2000;6:101-109.

52. Ishii M, Ota M, Saito S, Kinugasa Y, Akamoto S, Ito I. Lymphatic vessel invasion detected by monoclonal antibody D240 as a predictor of lymph node metastasis in T1 colorectal cancer. Int J Colorectal Dis 2009;24:1069-1074.

53. Ishikawa Y, Akishima-Fukasawa Y, Ito K, et al. Histopathologic determinants of regional lymph node metastasis in early colorectal cancer. Cancer 2008;112:924-933.

54. Kojima M, Puppa G, Kirsch R, et al. Blood and lymphatic vessel invasion in pT1 colorectal cancer: an international concordance study. J Clin Pathol 2015;68:628-632.

55. Suzuki A, Togashi K, Nokubi M, et al. Evaluation of venous invasion by Elastica van Gieson stain and tumor budding predicts local and distant metastases in patients with T1 stage colorectal cancer. Am J Surg Pathol 2009;33:1601-1607.

56. Wada H, Shiozawa M, Sugano N, et al. Lymphatic invasion identified with D2-40 immunostaining as a risk factor of nodal metastasis in T1 colorectal cancer. Int J Clin Oncol 2013;18:1025-1031.

57. Barel F, Auffret A, Cariou M, et al. High reproducibility is attainable in assessing histoprognostic parameters of pT1 colorectal cancer using routine histopathology slides and immunohistochemistry analyses. Pathology 2019;51:46-54.

58. WHO Classification of Tumours Editorial Board. Digestive System Tumours. 5th ed. Geneva: World Health Organization, 2019.

59. Kudo S, Tamegai Y, Yamano H, Imai Y, Kogure E, Kashida $\mathrm{H}$. Endoscopic mucosal resection of the colon: the Japanese technique. Gastrointest Endosc Clin N Am 2001;11:519-535.

60. Kouyama Y, Kudo SE, Miyachi H, et al. Practical problems of measuring depth of submucosal invasion in T1 colorectal carcinomas. Int J Colorectal Dis 2016;31:137-146.

61. Tanaka S, Kashida H, Saito Y, et al. JGES guidelines for colorectal endoscopic submucosal dissection/endoscopic mucosal resection. Dig Endosc 2015;27:417-434.

62. Oka S, Tanaka S, Saito Y, et al. Local recurrence after endoscopic resection for large colorectal neoplasia: a multicenter prospective study in Japan. Am J Gastroenterol 2015;110:697-707.

63. Saito Y, Uraoka T, Yamaguchi Y, et al. A prospective, multicenter study of 1111 colorectal endoscopic submucosal dissections (with video). Gastrointest Endosc 2010;72:12171225.

64. Overwater A, Kessels K, Elias SG, et al. Endoscopic resection of high-risk $\mathrm{T} 1$ colorectal carcinoma prior to surgical resection has no adverse effect on long-term outcomes. Gut 2018;67:284-290.

65. Yamashita K, Oka S, Tanaka S, et al. Preceding endoscopic submucosal dissection for T1 colorectal carcinoma does not affect the prognosis of patients who underwent additional 
surgery: a large multicenter propensity score-matched analysis. J Gastroenterol 2019;54:897-906.

66. Yamaoka Y, Imai K, Shiomi A, et al. Endoscopic resection of T1 colorectal cancer prior to surgery does not affect surgical adverse events and recurrence. Surg Endosc 2020;34:50065016.

67. Liu Y, Li R, Chang W, et al. The effect of non-curative endoscopic resection on CT1N0M0 colorectal carcinoma patients who underwent additional surgery. Surg Endosc 2021;35:2862-2869.

68. Rickert A, Aliyev R, Belle S, Post S, Kienle P, Kähler G. Oncologic colorectal resection after endoscopic treatment of malignant polyps: does endoscopy have an adverse effect on oncologic and surgical outcomes? Gastrointest Endosc 2014;79:951-960.

69. Watanabe D, Toyonaga T, Ooi M, et al. Clinical outcomes of deep invasive submucosal colorectal cancer after ESD. Surg Endosc 2018;32:2123-2130.

70. Schmidt A, Beyna T, Schumacher B, et al. Colonoscopic full-thickness resection using an over-the-scope device: a prospective multicentre study in various indications. Gut 2018;67:1280-1289.

71. Shahidi N, Bourke MJ. Endoscopic full-thickness resection for invasive colorectal neoplasia: hype or here to stay? Gastrointest Endosc 2019;89:1190-1192.

72. Guillaumot MA, Barret M, Jacques J, et al. Endoscopic fullthickness resection of early colorectal neoplasms using an endoscopic submucosal dissection knife: a retrospective multicenter study. Endosc Int Open 2020;8:E611-E616.

73. Dang H, de Vos Tot Nederveen Cappel WH, van der Zwaan SMS, et al. Quality of life and fear of cancer recurrence in T1 colorectal cancer patients treated with endoscopic or surgi- cal tumor resection. Gastrointest Endosc 2019;89:533-544.

74. Macias-Garcia F, Celeiro-Muñoz C, Lesquereux-Martinez L, et al. A clinical model for predicting lymph node metastasis in submucosal invasive (T1) colorectal cancer. Int J Colorectal Dis 2015;30:761-768.

75. Ichimasa K, Kudo SE, Mori Y, et al. Artificial intelligence may help in predicting the need for additional surgery after endoscopic resection of T1 colorectal cancer. Endoscopy 2018;50:230-240.

76. Kudo SE, Ichimasa K, Villard B, et al. Artificial intelligence system to determine risk of T1 colorectal cancer metastasis to lymph node. Gastroenterology 2021;160:1075-1084.

77. Korbar B, Olofson AM, Miraflor AP, et al. Deep learning for classification of colorectal polyps on whole-slide images. J Pathol Inform 2017;8:30.

78. Takamatsu M, Yamamoto N, Kawachi H, et al. Prediction of early colorectal cancer metastasis by machine learning using digital slide images. Comput Methods Programs Biomed 2019;178:155-161.

79. Ozawa T, Kandimalla R, Gao F, et al. A microRNA signature associated with metastasis of $\mathrm{T} 1$ colorectal cancers to lymph nodes. Gastroenterology 2018;154:844-848.

80. Kandimalla R, Ozawa T, Gao F, Wang X, Goel A; T1 Colorectal Cancer Study Group. Gene expression signature in surgical tissues and endoscopic biopsies identifies highrisk T1 colorectal cancers. Gastroenterology 2019;156:23382341.

81. Kishida Y, Oishi T, Sugino T, et al. Associations between loss of ARID1A expression and clinicopathologic and genetic variables in T1 early colorectal cancer. Am J Clin Pathol 2019;152:463-470. 